\title{
ПСИХОЛОГИЧЕСКАЯ ОСНОВА
}

САМОРЕАЛИЗАЦИИ СТУДЕНТОВ

В ИНТЕГРИРОВАННОЙ

ОБРАЗОВАТЕЛЬНОЙ СРЕДЕ

\section{The Psychological Basis of Students' Self-Realization at the Integrated Educational Environment}

\author{
Ivan Danyliuk \\ Taras Schevchenko National University of Kyiv, Ukraine \\ Olga Kuprieieva \\ Taras Schevchenko National University of Kyiv, Ukraine
}

\begin{abstract}
In the space of modern Ukrainian higher education, the tasks of vocational training development and improvement, integration and creating conditions for disabled students' creative self-realization become really important. In order to create the structure of adapted environment at universities and to promote personal and professional development of all participants at the integrated educational environment, a comprehensive psychological study of the psychological foundations of students' personal self-realization should be done. The research objective: to study psychological characteristics of students' self-realization studied at integrated groups with investigation of disabled students' self-attitudes and their correlations with self-actualization, meaningful life orientations and psychological hardiness. Research methods: the test-questionnaire of self-attitudes (S. Pantileev, V. Stolin); Shostrom's Personal Orientation Inventory in adaptation N. Kalin, A.Lazukin; the Test of Meaningful Life Orientation of D.L. Leontev; S. Maddi's Hardiness Scale in adaptation of D. Leontiev, Ye.I. Raskasova; the methods of statistical analysis for empirical data: comparative analysis of average indicators, correlation analysis. The performed empirical study revealed such psychological characteristics of disabled students' self-attitudes as unrealistic ideas about themselves, their abilities and skills, a tendency to self-blame, low level of self-understanding, which can become obstacles to their effective self-realization. The success of students' selfrealization in the integrated educational environment of universities is provided by their internal resources: positive self-attitude, awareness of goals, meanings in life, strength and stability of Self, cooperation with other people, society as a whole.
\end{abstract}

Keywords: an integrated educational environment, meaningful life orientations, psychological hardiness, self-realization, self-attitude, students with disabilities. 
Danyliuk \& Kuрrieieva, 2020. Психологическая основа самореализации студентов в интегрированной образовательной среде

\section{Введение \\ Introduction}

Современное образование - это важнейшая часть жизни человека и фактор его самореализации. Поэтому должно быть направлено на актуализацию и развитие ресурсов самореализации личности, жизненных и профессиональных целей, ценностей и смысла жизни, жизнестойкости, свободы и ответственности.

Особую актуальность проблема самореализации личности приобретает в юношеском возрасте, для которого характерны поиск оптимального смысла жизни, жизненных целей, потребность достижения личностной идентичности, трансформация системы ценностей, социальное, личностное и профессиональное самоопределение.

Это в полной мере касается студентов с инвалидностью, для которых возможность получения образования и приобретение профессии эффективное средство социальной востребованности, социокультурной, экономической мобильности, свободы выбора жизненных целей и личностной самореализации.

Актуальность данного исследования обусловлена практической необходимостью изучения психологических особенностей самореализации студентов с инвалидностью, как формы в которой человек обеспечивает свое развитие и саморазвитие, и содействия этому процессу в условиях интегрированной образовательной среды.

Цель исследования: изучение особенностей самореализации студентов в интегрированной образовательной среде, через диагностику самоотношения студентов с инвалидностью и условно здоровых студентов, выявление взаимосвязей самоотношения с самоактуализацией, смысложизненными ориентациями и жизнестойкостью личности.

Методы исследования. Опросник самоотношения личности (Pantileev, 1993); модифицированный опросник диагностики самоактуализации личности А. Лазукин, Н. Калина (Fetiskin, Kozlov, \& Manujlov, 2002); методика исследования смысложизненных ориентаций (Leont'ev, 2000); тест жизнестойкости С. Мадди, (Leont'ev \& Rasskazova, 2006).

\section{Обзор литературы Review of the Literature}

Существующие в психологии близкие по смыслу понятия самореализация, самоактуализация, саморазвитие, самоопределение, самоутверждение, самовыражение, саморазвитие, самоактивность, самодетерминация в достаточной мере не имеют однозначного объяснения. Очевидно, 
что “само” предполагает нечто идущее из внутреннего, самопричинное, побуждаемое и регулируемое изнутри (Klochko \& Galazhinskij, 1999). А это, безусловно, сложный для исследования и понимания феномен.

Все эти понятия содержат основную гуманистическую идею А. Маслоу (Maslou, 2008) о врожденной тенденции, присущей всем без исключения людям, о реализации собственных потенциальных возможностей и способностей.

Самореализация - это процесс актуализации и реализации индивидуальности личности, ее внутреннего позитивного и творческого потенциала развития, психологической зрелости и компетентности.

Это процесс самопознания своих способностей, возможностей, образа «Я», смыслов существования (Selezneva, 2015); перевод их из состояний возможностей (потенциального) в действительность (актуальность) (Klochko \& Galazhinskij, 1999); реализация их в реальных условиях взаимодействия с окружающим миром и людьми (Walker et al., 2011); способность человека реалистично воспринимать себя, свои возможности, способности и использовать их для планирования обучения, овладения профессиональными навыками и построения жизнедеятельности в целом (Wehmeyer et al., 2007).

Согласно концепции, К. Роджерса (Rodzhers, 2002) человек развивается в направлении самореализации только самостоятельно, никто не может в этом направлении его подталкивать. При этом, должны быть сформированы принципиально важные личностные характеристики: степень активности собственных усилий личности (внутренний локус контроля, внутренняя мотивация, воля, автономия, система ценностных ориентаций) как компоненты и условия эффективной самореализации личности (Serdyuk, 2014).

Человек живет и развивается в конкретных социокультурных условиях, в непосредственном взаимодействии с другими людьми, и его личностное развитие обусловлено системой его основных отношений (к себе, окружающему миру, другим людям), которые являются относительно стабильными и образуют целостность личности (Selezneva, 2015), «Я-концепцию» (Rodzhers, 2002) и самоотношение.

Самоотношение тесно связано с «Я-концепцией» индивида, как динамической системой установок, направленных на саму личность. Отсюда, позитивную «Я-концепцию» можно рассматривать как позитивное отношение к себе, самоуважение, принятие себя, ощущение собственной ценности. И наоборот синонимами негативной «Я-концепции» становится негативное отношение к себе, непринятие, ощущение своей нереализованности. Именно позитивная, «конгруэнтная Я-концепция» (Rodzhers, 2016), является основным условием личностного роста и самореализации. 
Danyliuk \& Kuprieieva, 2020. Психологическая основа самореализачии студентов в интегрированной образовательной среде

Самоотношение как компонент самосознания обуславливает процессы самоопределения и самореализации, выступает как их результат (Kolyshko, 2012); обеспечивает оценку человеком своих характеристик, способствующих или препятствующих самореализации (Selezneva, 2015); регулирует межличностное взаимодействие, постановку и достижение целей и как сложное когнитивно-аффективное образование обуславливает эмоционально-ценностное принятие себя (Pantileev, 1993). Развитие самосознания, позитивное реалистичное отношение к себе (способность оценить свои сильные стороны, сложности, потребности) связаны с личной автономией, самодетерминацией личности, с возможностью устанавливать и реализовывать цели, контролировать свою жизнь (Ankeny \& Lehmann, 2011).

Отношение к собственному «Я» формируется в зависимости от того воспринимается оно позитивным, негативным или конфликтным (Stolin, 1983). Позитивное самоотношение фиксируется сознанием, в определенный период времени, как интегральное ощущение благополучия. Негативное и конфликтное самоотношение как субъективное ощущение неблагополучия. Таким образом, самоотношение, может быть, как ресурсом (позитивное отношение к себе), так и барьером (негативное или конфликтное отношение к себе) саморазвития и самореализации личности.

Самоотношение как ценность «Я», тесным образом связано с личностными ценностями, смыслами и активностью личности. В результате взаимодействия с ценностно-мотивационными образованиями личности и жизнестойкостью, как базовой характеристикой личности, которая опосредует воздействие на ее сознание и поведение всевозможных неблагоприятных обстоятельств (Maddi, 2006, 2013) (в данном случае соматических заболеваний), самоотношение включается в процесс деятельности и личностной самоэффективности, саморегуляции; стимулирует развитие познавательной активности, субъектности человека, автономной мотивации, способствует психологическому здоровью и благополучию, как характеристики зрелой личности (Ryan \& Deci, 2017).

Таким образом, регуляторное влияние самоотношения определяется широтой его включенности в процесс самореализации и влияет на проявление субъектной активности личности.

\section{Методология Methodology}

В исследовании были использованы: опросник самоотношения личности (Pantileev, 1993); модифицированный опросник самоактуализации личности А. Лазукина, Н. Калиной (Fetiskin, Kozlov, \& Manujlov, 2002); методика исследования смысложизненных ориентаций Д. Крамбо та 
Л. Махолика (Leont'ev, 1992); тест жизнестойкости С. Мадди, (Leont'ev \& Rasskazova, 2006).

В эмпирическом исследовании приняли участие 453 студента, обучающихся в интегрированных группах университетов г. Киева, (Украина). И них: 215 студентов с инвалидностью (с заболеваниями опорнодвигательно-го аппарата, детским церебральным параличом, заболеваниями органов зрения, органов слуха, общие заболевания, заболевания нервной системы) и 238 условно здоровых студентов. Возраст испытуемых от 18-21 года.

Методы статистического анализа эмпирических данных: сравнительный анализ среднестатистических показателей, корреляционный, регрессионный анализ производился с помощью компьютерной программы для статистической обработки данных SPSS Statistics 21.0.

\section{Результаты и дискуссия Results and Discussion}

С целью исследования особенностей самоотношения мы использовали опросник самоотношения (Pantileev, 1993). У значительной части респондентов выявлены средние (5-12) и высокие (больше 12 балов) показатели, сравнивая полученные данные с нормативными показателями (Pantileev, 1993). На Рисунке 1 представлены средние значения показателей самоотношения.

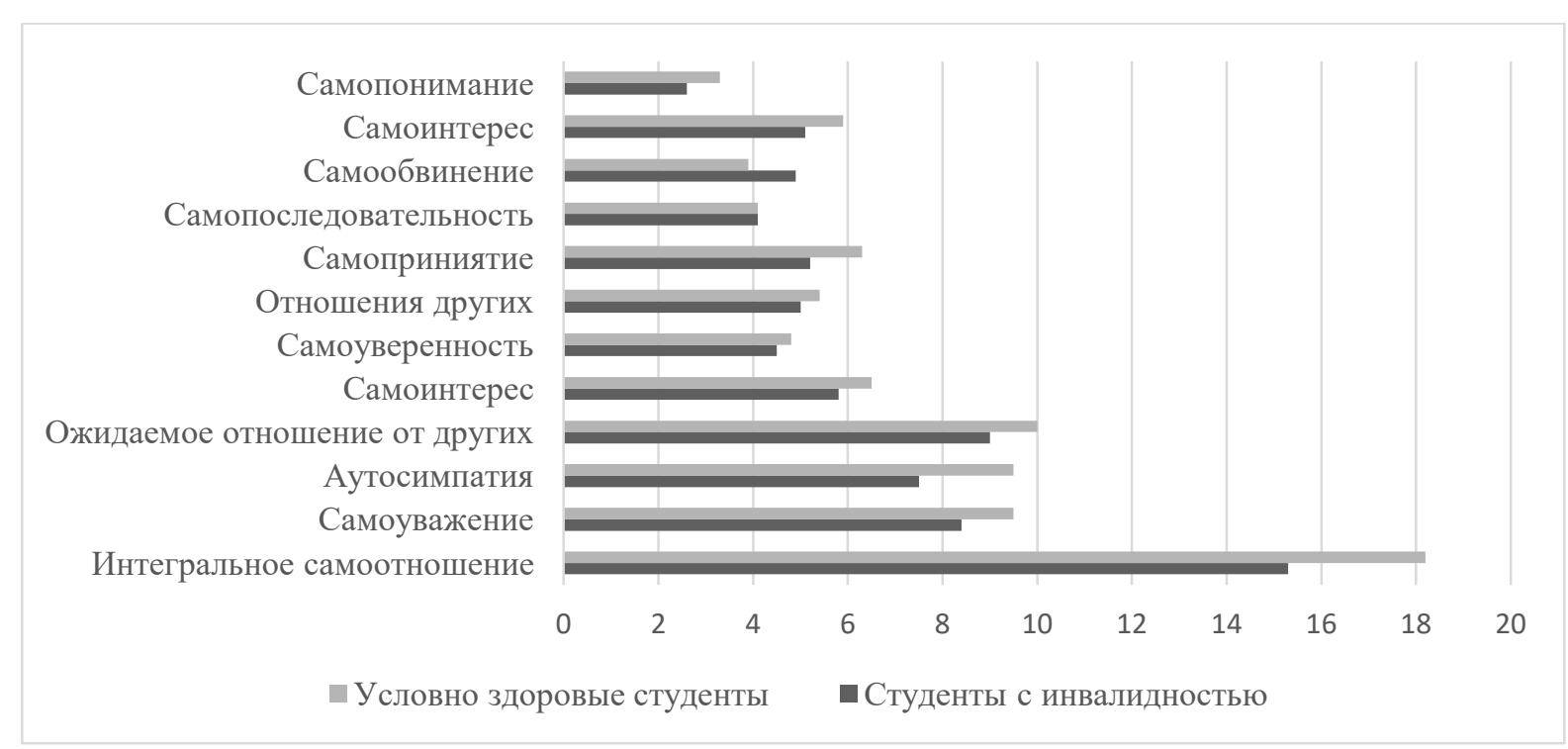

Рисунок 1. Средние значения показателей самоотночения студентов с инвалидностью и условно здоровых студентов

Figure 1 Average values of self-attitude indicators scored by students with disabilities and relatively healthy students 
Danyliuk \& Kuprieieva, 2020. Психологическая основа самореализачии студентов в интегрированной образовательной среде

Структура самоотношения у респондентов отличается выраженностью его компонентов. У студентов с инвалидностью средние показатели по всем компонентам самоотношения ниже, а по «самообвинению» выше, чем у условно здоровых студентов (Рисунок 1). Это может свидетельствовать о том, что для студентов с инвалидностью характерно нереалистичное представление о себе, своих возможностях, способностях. Они склонны к самообвинению, что может снижать их способность действовать в соответствии со своими предпочтениями, убеждениями; делает их зависимыми от внешнего влияния, вмешательства и может является барьером эффективной самореализации.

Можно предположить, что функционирование и поддержание собственного «Я», у исследуемых студентов, осуществляется за счет разного соотношения показателей самоотношения. Так, наиболее важную роль в способности испытуемых прогнозировать, контролировать свою деятельность, взаимодействовать с самим собой и окружающим миром, играет «интегральное самоотношение», «аутосимпатия», «самоуважение» и «ожидаемое отношение от других». Ожидаемая высокая внешняя оценка других, при низком самопонимании, недостаточности собственного опыта, в студенческом возрасте, еще остается важным фактором развития отношения к собственному «Я».

С целью сравнение показателей самоотношения, смысложизненных ориентаций, самоактуализации и жизнестойкости личности студентов мы использовали методики: опросник самоотношения личности (Pantileev, 1993); модифицированный опросник самоактуализации личности A. Лазукина, Н. Калиной (Fetiskin, Kozlov, \& Manujlov, 2002); методику исследования смысложизненных ориентаций Д. Крамбо та Л. Махолика (Leont'ev, 1992); тест жизнестойкости С. Мадди, (Leont'ev \& Rasskazova, 2006). В Таблице 1 указаны выявленные, значимые различия, в психологических характеристиках респондентов.

Значимые различия выявлены по параметрам: «интегральное самоотношение», «самоуверенность», «самоинтерес», «самоуважение»; самоактуализации: «автономность», «контактность»; смысложизненных ориентаций «результат жизни», «процесс жизни»; «жизнестойкость» (Таблица 1). Данные параметры у студентов с инвалидностью выражены слабее, чем у условно здоровых студентов. Можно предположить, что студентам с инвалидностью, как и условно здоровым студентам, присуще стремление к самоактуализации. Однако, неуверенность в себе, низкий уровень самопонимания, принятия себя, отображается в нереалистичном, часто конфликтном отношении к себе, оценке своих сильных, потенциальных способностей и возможностей, интегрированности отношения к собственному «Я». Что в свою очередь может препятствовать 
осознанию жизненных целей, способности действовать автономно, быть включенным, регулировать, контролировать и нести ответственность за события своей жизни, по средствам личностной активности.

\section{Таблица 1. Сравнение показателей выборки студентов с инвалидностью и условно здоровых студентов}

Table 1 Comparison of indicators of students with disabilities and relatively healthy students

\begin{tabular}{|c|c|c|c|c|c|c|}
\hline \multirow{3}{*}{ Показатели } & \multicolumn{6}{|c|}{ t критерий равенства средних } \\
\hline & \multirow[t]{2}{*}{ F } & \multirow[t]{2}{*}{$\begin{array}{c}\text { Уровень } \\
\text { значимости }\end{array}$} & \multirow[t]{2}{*}{$\mathrm{t}$} & \multirow[t]{2}{*}{$\begin{array}{l}\text { Уровень } \\
\text { значимости }\end{array}$} & \multicolumn{2}{|c|}{$\begin{array}{l}\text { 95\% } \\
\text { доверительный } \\
\text { интервал }\end{array}$} \\
\hline & & & & & $\begin{array}{l}\text { нижняя } \\
\text { граница }\end{array}$ & $\begin{array}{l}\text { верхняя } \\
\text { граница }\end{array}$ \\
\hline Интегральное самоотношение & 11,43 & 0,001 & 5,37 & 0,00 & 1,81 & 3,92 \\
\hline Самоуважение & 7,78 & 0,005 & 3,01 & 0,00 & 0,25 & 1,21 \\
\hline Самоуверенность & 13,74 & 0,00 & 1,56 & 0,11 & $-0,08$ & 0,70 \\
\hline Отношение других & 7,78 & 0,001 & 2,68 & 0,10 & 0,02 & 0,75 \\
\hline Самоинтерес & 9,15 & 0,003 & 4,70 & 0,00 & 0,50 & 1,24 \\
\hline Автономность & 18,88 & 0,00 & 1,79 & 0,07 & $-0,39$ & 8,42 \\
\hline Аутосимпатия & 3,58 & 0,005 & 2,39 & 0,01 & 0,93 & 9,68 \\
\hline Контактность & 6,76 & 0,01 & 1,75 & 0,05 & $-0,44$ & 7,81 \\
\hline Самоактуализации & 3,87 & 0,005 & 3,28 & 0,00 & 1,48 & 5,94 \\
\hline Процесс жизни & 11,53 & 0,00 & 4,24 & 0,00 & 1,79 & 4,89 \\
\hline Результативность жизни & 23,92 & 0,00 & 1,35 & 0,17 & $-0,43$ & 2,33 \\
\hline Локус контроля - жизнь & 3,40 & 0,006 & 3,29 & 0,00 & 1,13 & 4,50 \\
\hline Вовлеченность & 4,55 & 0,001 & 3,57 & 0,00 & 1,71 & 5,90 \\
\hline Контроль & 4,23 & 0,002 & 1,89 & 0,01 & $-0,08$ & 3,36 \\
\hline Принятие риска & 4,55 & 0,003 & 2,86 & 0,05 & 0,53 & 2,88 \\
\hline Жизнестойкость & 8,74 & 0,001 & 3,92 & 0,01 & 2,96 & 11,78 \\
\hline
\end{tabular}

Для выявления взаимосвязи самоотношения с характеристиками личности (самоактуализацией, жизнестойкостью, смысложизненными ориентациями) мы использовали интегральные показатели самоотношения опросника самоотношения личности (Pantileev, 1993), базовые шкалы модифицированного опросника самоактуализации личности А. Лазукина, H. Калиной (Fetiskin, Kozlov, \& Manujlov, 2002); методику исследования смысложизненных ориентаций Д. Крамбо та Л. Махолика (Leont'ev, 1992); тест жизнестойкости С. Мадди, (Leont'ev \& Rasskazova, 2006).

Нами выявлены значимые позитивные корреляционные связи самоотношения и его интегральных показателей с базовыми шкалами самоактуализационного теста, как у студентов с инвалидность, так и у условно здоровых студентов (Таблица 2).

Можно предположить, что высокий уровень самоотношения и его интегрированность обуславливают наличие у студентов ценностей 
Danyliuk \& Kuprieieva, 2020. Психологическая основа самореализаџии студентов в интегрированной образовательной среде

самореализации, способности переживать настоящий момент свей жизни во всей его полноте, стремление актуализировать свои способности и возможности. Уверенность в себе в сочетании с осознанностью, так же, обуславливает формирование важной характеристики самоактуализирующейся личности - потребности в автономии. Однако, не сформированность личностной рефлексии, как механизма познанияи понимания себя, может снижать потребность в познании. Низкие показатели корреляционных связей, и их отсутствие, самоотношения и его интегральных характеристик, с «потребностью в познании» диагностированы у условно студентов.

Таблица 2. Взаимосвязь интегральных показателей самоотношения и показателей самоактуализации, жсизнестойкости, смысложизненных ориентаций

Table 2 Correlation between the integral self-attitude and indicators of self-actualization, psychological hardiness, meaningful life orientations

\begin{tabular}{|c|c|c|c|c|c|c|c|c|c|c|}
\hline & \multicolumn{2}{|c|}{$\begin{array}{l}\text { Интегральное } \\
\text { самоотношение }\end{array}$} & \multicolumn{2}{|c|}{ Самоуважение } & \multicolumn{2}{|c|}{ Аутосимпатия } & \multicolumn{2}{|c|}{$\begin{array}{l}\text { Ожидаемое } \\
\text { отношение } \\
\text { от других }\end{array}$} & \multicolumn{2}{|c|}{ Самоинтерес } \\
\hline & 1 & 2 & 1 & 2 & 1 & 2 & 1 & 2 & 1 & 2 \\
\hline $\begin{array}{l}\text { Ориентация во } \\
\text { времени }\end{array}$ &, $27^{* *}$ &, $25^{* *}$ & $35^{* *}$ & $16^{*}$ &, $24^{* *}$ & 21 & ,07 &, $14^{* *}$ &, $19^{* *}$ & ,03 \\
\hline Ценности &, $65^{* *}$ &, $32^{* *}$ &, $58^{* *}$ & $23^{* *}$ &, $54^{* *}$ & ,27 & $31^{* *}$ & ,16 & $24^{* *}$ &, 07 \\
\hline $\begin{array}{l}\text { Потребность в } \\
\text { познании }\end{array}$ &, $29^{* *}$ & ,16 &, $37^{* *}$ & $18^{*}$ &, $27^{* *}$ & ,06 &, $14^{*}$ & ,02 &, $21^{* *}$ & ,02 \\
\hline Автономность & $23^{*}$ &, $27^{* *}$ &, $21^{*}$ & $21^{*}$ &, $25^{* *}$ & $28^{* *}$ &,- 09 & ,12 & ,-04 &, 10 \\
\hline Самоактуализация & $42^{* *}$ &, $40^{* *}$ &, $37^{* *}$ & $25^{* *}$ &, $36^{* *}$ & $33^{* *}$ & ,12 &, $18^{*}$ & ,15 & ,14 \\
\hline Вовлеченность &, $57^{* *}$ &, $56^{* *}$ &, $53^{* *}$ & $47^{* *}$ &, $50^{* *}$ &, $34^{* *}$ &, $22^{* *}$ &, $36^{* *}$ &, $22^{* *}$ &, $17^{*}$ \\
\hline Контроль &, $53^{* *}$ &, $56^{* *}$ &, $59^{* *}$ &, $53^{* *}$ & $43^{* *}$ & $40^{* *}$ & $16^{*}$ &, $24^{* *}$ &, $14^{*}$ &, $21^{*}$ \\
\hline Принятие риска & $46^{* *}$ &, $55^{* *}$ &, $53^{* *}$ & $42^{* *}$ & $45^{* *}$ & $41^{* *}$ & $19^{* *}$ &, $30^{* *}$ & 11 & $23^{* *}$ \\
\hline Жизнестойкость &, $60^{* *}$ & $62^{* *}$ &, $62^{* *}$ &, $54^{* *}$ &, $53^{* *}$ &, $42^{* *}$ &, $20^{* *}$ & $34^{* *}$ &, $19^{* *}$ & $22^{* *}$ \\
\hline Цели в жизни &, $67^{* *}$ & $37^{* *}$ &, $57^{* *}$ & $37^{* *}$ &, $54^{* *}$ & $28^{* *}$ & $37^{* *}$ & $28^{* *}$ &, $30^{* *}$ & $19^{*}$ \\
\hline Процесс жизни &, $56^{* *}$ &, $37^{* *}$ &, $42^{* *}$ & $26^{* *}$ &, $42^{* *}$ & $30^{* *}$ & $36^{* *}$ &, $24^{* *}$ &, $22^{*}$ &, $22^{*}$ \\
\hline $\begin{array}{l}\text { Результативность } \\
\text { жизни }\end{array}$ &, $64^{* *}$ &, $45^{* *}$ &, $63^{* *}$ & $33^{* *}$ &, $55^{* *}$ & $35^{* *}$ & $37^{* *}$ &, $35^{* *}$ &, $23^{*}$ &, $21^{*}$ \\
\hline Локус контроля-Я & $45^{* *}$ &, $34^{* *}$ &, $37^{* *}$ & $27^{* *}$ & $30^{* *}$ &, $27^{* *}$ & $27^{* *}$ & $30^{* *}$ & $33^{* *}$ & $21^{*}$ \\
\hline $\begin{array}{l}\text { Локус контроля- } \\
\text { жизнь }\end{array}$ &, $60^{* *}$ &, $43^{* *}$ &, $43^{* *}$ &, $33^{* *}$ &, $45^{* *}$ &, $36^{* *}$ &, $38^{* *}$ & $22^{*}$ & $33^{* *}$ &, $24^{* *}$ \\
\hline
\end{tabular}

Примечание: 1 - испытуемые студенты с инвалидностью; 2 - испытуемые условно здоровые студенты; ** - корреляция достоверна на уровне $p \leq 0,001$; *на уровне $-p \leq 0,05$

Интегральные показатели самоотношения значимо коррелируют с жизнестойкостью личности и ее составляющими. Это свидетельствует о том, что позитивное отношение к себе, личностная идентичность стимулируют активность собственных усилий, направленных на включенность в процесс жизни, способность контролировать жизненные 
Proceedings of the International Scientific Conference. Volume IV, May $22^{\text {th }}-23^{\text {th }}, 2020.17-29$

события, нести ответственность за них, преодолевать трудности и выдерживать напряжение, связанное с ними. Эти результаты согласуются с результатами исследования психологических факторов жизнестойкости старшеклассников (Serdiuk, Danyliuk, \& Chykhantsova, 2019).

Самоотношение и его интегральные характеристики, у испытуемых студентов, тесно связаны со смысложизненными ориентациями. Причем, у студентов с инвалидностью корреляционные связи со всеми показателями смысложизненных ориентаций выше, чем у условно здоровых студентов (Таблица 2). Позитивное самоотношение, основанное на самоуважении и аутосимпатии, усиливает осознанность и поддержания личностных смыслов, целостности настоящего (насыщенность жизни), прошлого (удовлетворенность самореализацией) и будущего (цели в жизни). Эти результаты согласуются с данными исследования (Wehmeyer et al., 2007), которые показывают, что самоотношение и самопознание, как составляющие самодетерминации, влияют на постановку целей и достижения успехов в обучении студентов с инвалидностью.

На основе регрессионного анализа мы определили какие из независимых переменных существенны и значимы для прогноза показателя самоотношения. В качестве независимых переменных мы использовали базовые шкалы модифицированного опросника самоактуализации личности А. Лазукина, Н. Калиной (Fetiskin, Kozlov, \& Manujlov, 2002); показатели методики исследования смысложизненных ориентаций Д. Крамбо та Л. Махолика (Leont'ev, 1992) и теста жизнестойкости С. Мадди, (Leont'ev \& Rasskazova, 2006).

Результаты моделей регрессионного анализа в выборке студентов с инвалидностью поданы в Таблице 3.

Таблица 3. Модель регрессионного анализа для показателя «самоотношение» выборки студентов с инвалидностью

Table 3 The model of regression analysis for 'self-attitudes' indicator of students with disabilities

\begin{tabular}{|c|c|c|c|c|}
\hline Модель & $\mathrm{R}$ & R-квадрат & $\begin{array}{c}\text { Скорректированный } \\
\text { R-квадрат }\end{array}$ & $\begin{array}{c}\text { Стандартная } \\
\text { ошибка оценки }\end{array}$ \\
\hline 1 & $.667^{\mathrm{a}}$ & .445 & .439 & 3,497 \\
\hline 2 & $.687^{\mathrm{b}}$ & .472 & .462 & 3.423 \\
\hline 3 & $.713^{\mathrm{c}}$ & .511 & .493 & 3.370 \\
\hline
\end{tabular}

а. Предикторы: (конст) ичели в жизни

b. Предикторы: (конст) цели в жизни, потребность в познании

c. Предикторы: (конст) ичели в жизни, потребность в познании, вовлеченность

d. Зависимая переменная: самоотномение 
Danyliuk \& Kuprieieva, 2020. Психологическая основа самореализачии студентов в интегрированной образовательной среде

Достоверной является модель 3, которая объясняет 51\% дисперсии. То есть, наиболее точно прогнозирует значение показателя самоотношения, модель, которая включает предикторы: цели в жизни, потребность в познании, вовлеченность.

Результаты модели регрессионного анализа в выборке условно здоровых студентов поданы в Таблице 4.

Таблица 4. Модель регрессионного анализа для показателя «самоотночение» выборки условно здоровых студентов

Table 4 The model of regression analysis for 'self-attitudes' indicator of relatively healthy students

\begin{tabular}{|c|c|c|c|c|}
\hline Модель & $\mathrm{R}$ & R-квадрат & $\begin{array}{c}\text { Скорректированный } \\
\text { R-квадрат }\end{array}$ & $\begin{array}{c}\text { Стандартная } \\
\text { ошибка оценки }\end{array}$ \\
\hline 1 & $.621^{\mathrm{a}}$ & .386 & .381 & 2.798 \\
\hline 2 & $.722^{\mathrm{b}}$ & .560 & .490 & 3.726 \\
\hline
\end{tabular}

а. Предикторы: (конст.) жизнестойкость

b. Предикторы: (конст.) жизнестойкость, результативность жизни

c. Зависимая переменная: самоотношение

Модель 2 является достоверной, поскольку, полученное значение $\mathrm{R}$-квадрат превышает 0,5 . Наиболее точно прогнозирует значение показателя самоотношения, условно здоровых студентов, модель, в которую входят предикторы жизнестойкость и результативность жизни.

Выявленные предикторы свидетельствуют, о том, что осознанность жизненных целей, потребность в познании себя и окружающего мира, вовлеченность в собственную жизнь, в большей мере, обуславливают самореализацию студентов с инвалидностью. Жизнестойкость и результативность жизни (или удовлетворенность самореализацией) являются предикторами, обеспечивающими процесс самореализации условно здоровых студентов, а их не сформированность, могут значительно усложнять, и даже, деформировать саморазвитие личности.

\section{Выводы Conclusions}

Самоотношение является одной из важных детерминант самореализации личности и в значительной мере обеспечивает степень личностной активности в постановке и достижении целей, целостности личности, эффективности ее отношений к себе, к миру в целом.

Выявленные психологические особенности самоотношения студентов с инвалидностью (нереалистичное представление о себе, своих возможностях и способностях, склонность к самообвинению, низкий 
уровень самопонимания и самопоследовательности) могут быть препятствиями их эффективной самореализации. Позитивное самоотношение может поддерживаться развитием таких его ресурсных компонентов, как самоинтерес, самопонимание и самопринятие.

Успешность самореализации и студентов с инвалидностью, и условно здоровых студентов, обуславливается:

- сформированностью позитивного самоотношения, как смыслового образования личности, и его компонентов;

- мерой активности собственных усилий, направленных на включенность в собственную жизнь, способность регулировать и контролировать ее события, принимать вызовы и нести ответственность за результативность своей жизни;

- осознанностью целей и смыслов собственной жизни, способностью к самоуправлению, самоконтролю, самоорганизации своей деятельности, то есть включенностью в жизнь;

- включенностью студентов в интегрированное образовательное пространство вуза, основными ценностями которого должны быть - личностное развитие, гуманизм, творческая самореализация. Позитивное взаимодействие со студентами, преподавателями вуза, психологическая поддержка и содействие помогают развивать социальную компетентность всех участников интегрированной образовательной среды.

\section{Summary}

The article presents the results of the empirical study on self-realization of students studied in the integrated educational environment of universities, in the context of self-attitudes of students with disabilities and conditionally healthy students. It is determined that an individual's self-realization, as an integral phenomenon, is mediated by a set of interconnected personal characteristics, in particular self-attitude, the values of self-development and selfactualization, awareness of life goals, and psychological hardiness.

The article theoretically substantiates that self-attitude is one of the most important determinants of an individual's self-development and self-realization; self-attitude is closely connected with self-concept, as a dynamic system of attitudes aimed at an individual him/herself; the regulatory influence of self-attitude is determined by deepness of its involvement into self-developmental processes; self-attitude affects manifestations of an individual's subjective activities.

The psychological peculiarities of disabled students' self-attitudes are revealed: an unrealistic view on themselves, their capabilities and skills, which deforms their life goals, plans; they are prone to self-blaming, which reduces their ability to act in accordance with their preferences, beliefs and makes them dependent on external influences.

The high self-attitude and conjunction of its indicators determine the students' selfrealization values, their ability to experience acurrent moment of their life in its entirety, their desire to actualize their capabilities. 
Danyliuk \& Kuprieieva, 2020. Психологическая основа самореализаџии студентов в интегрированной образовательной среде

Positive self-attitude, self-respect and auto-sympathy enhance an individual's ability to understand and maintain personal meanings, to feel integrity of the present (richness of life), past (satisfaction with self-realization) and future (goals in life).

The formation of a positive self-attitude, which underlies an integrated self-image, determines the measure of one's own efforts aimed at inclusion into life in order to control life events, bear responsibility for them, overcome difficulties and withstand stresses.

\section{Литература \\ References}

Ankey, E.M., \& Lemann, J. P. (2011). Journey toward Self-Determination: Voices of Students with Disabilities Who Participated in a Secondary Transition Program on a Community College Campus. Sage journals, 32(4), 279-289. DOI: https//doi.org/10.1177/ 0741932510362215

Fetiskin, N.P., Kozlov, V.V., \& Manujlov, G.M. (2002). Sotsial'no-psikhologicheskaya diagnostika razvitiya lichnosti I malykh grupp. M.: Progress, 426-433.

Klochko, V.E., \& Galazhinskij, EH.V. (1999). Samorealizatsiya lichnosti: sistemnyj vzglyad. Tomsk: Izdatel'stvo Tomskogo universiteta. Retrieved from http://vital.lib.tsu.ru/vital/ access/manager/Repository/vtls:000112507

Kolyshko, A.M. (2012). Vliyanie smyslozhiznennogo krizisa na samootnoshenie lichnosti v period rannej zrelosti. Psihologicheskie problemy smysla zhizni i akme: Elektronnyj sbornik materialov XVII simpoziuma. Retrieved from http://www.pirao.ru/ru/news/ detail.php?ID=6812

Leont'ev, D., \& Rasskazova, E. (2006). Test zhiznestojkosti. M.: Smysl. Retrieved from https://www.aksp.ru/work/activity/nac_strateg/resurs_centr/files/soln_testgizn.pdf

Leont'ev, D.A. (2000). Test smyslozhiznennykh orientatsij (SZHO).M.: Smysl. Retrieved from http://publishing.smysl.ru/book/sgo/ManSGO.pdf

Maslou, A. (2008). Motivatsiya I lichnost'. SPb. Piter. Retrieved from http://www.bimbad.ru/docs/maslow_motivation_and_personality.pdf

Maddi, S.R. (2006). Hardiness: The courage to grow from stresses. The Journal of Positive Psychology, 1(3), 160-168. DOI: 10.1080/17439760600619609

Maddi, S.R. (2013). Hardiness. Turning stressful circumstances into resilient growth. Springer Netherlands, Irvine, CA. DOI 10.1007/978-94-007-5222-1

Pantileev, S.R. (1993). Metodika issledovaniya samootnosheniya. M: Smysl. Retrieved from http://lib.mgppu.ru/opacunicode/app/webroot/index.php?url=/notices/index/IdNotice:24 1533/Source:default

Rodzhers, K. (2002). Svoboda uchit'sya. M.: Smysl. Retrieved from http://lib.mgppu.ru/opacunicode/app/webroot/index.php?url=/notices/index/IdNotice:11 503/Source:default

Rodzhers, K. (2016). Stanovlenie lichnosti. Vzglyad na psikhoterapiyu. M.: Institut obshhegumanitarnykh issledovanij. Retrieved from https://royallib.com/book/ rodgers_karl/o_stanovlenii_lichnostyu.html

Ryan, R.M., \& Deci, E.L. (2017). Self-determination theory: Basic psychological needs in motivation, development, and wellness. New York, NY, US: Guilford Press. DOI: 10.7202/1041847ar

Selezneva, E.V. (2015). Grani samoosushestvleniya: ot samootnosheniya $k$ samorealizacii: monografiya. M.-Berlin: Direkt-Media. Retrieved from: https://pps.ranepa.ru/ Publication2/2015/d2d7bbbc-d0bf-e611-80d0-005056a06105/55f947312ebba.pdf 
Serdyuk, L.Z. (2014). Osobystisnyj modus samorealizaciy I majbutnix faxivciv. Visnyk pislyadyplomnoyi osvity, 10(23), 239-248. Retrieved from http://nbuv.gov.ua/ UJRN/Vpo_2014_10_25

Serdiuk, L., Danyliuk, I., \& Chykhantsova, O. Psychological factors of secondary school graduates' hardiness. Social Welfare: Interdisciplinary Approach, 1, 93-103. DOI: https://doi.org/10.21277/sw.v1i9.454

Stolin, V.V. (1983). Samosoznanie lichnosti. M.: Izdatelstvo MGU. Retrieved from http://psylib.org.ua/books/stolv01/index.htm

Walker, H.M., Calkins, C., Wehmeyer, M.L., Walker, L., Bacon, A., Palmer, S.B., \& Johnson, D.R. (2011). A social-ecological approach to promote self-determination. Exceptionality, 19, 6-18. DOI:10.1080/09362835.2011.537220

Wehmeyer, M.L., Palmer, S.B., Soukup, J.H., Garner, N.W., \& Lawrence, M. (2007). SelfDetermination and Student Transition Planning Knowledge and Skills: Predicting Involvement. Exceptionality, 15(1), 31-44. DOI: 10.1207/s15327035ex1501_4 